Mnemosyne, Vol. XLV, Fasc. 4 (1992)

\title{
SOME NOTES ON THE EDITION OF TZETZES' ILIAS-EXEGESIS
}

BY

\section{INEKE SLUITER ${ }^{1}$ )}

In 1981, Anastasios Lolos published Johannes Tzetzes' notes on Iliad A 97-6092) in anticipation of his complete edition of Tzetzes' Ilias-Exegesis, which to the best of my knowledge has not appeared yet. The book received some attention, and much detailed criticism has been put forward, especially in two articles by Iakov ${ }^{3}$ ). Undoubtedly Lolos deserves credit for disclosing this text for us. But it is very difficult to extricate his critical principles from the exceedingly brief introduction and it is a fact that the text as it stands is often unintelligible, although the editor shows no signs of $\operatorname{alarm}^{4}$ ). In the following I will make some additions to the exten-

1) Research for this article has been made possible by a fellowship of the Royal Netherlands Academy of Arts and Sciences. I would like to thank Professors D.M. Schenkeveld and C.J. Ruijgh and the members of the 'Amsterdamse Hellenistenclub' for their helpful criticism of an carlier draft of this paper.

2) Der Unbekannte Teil der Ilias-Exegesis des Iohannes Tzetzes: (A 97-609), Königstein/Ts. Parts of this text were published earlier, see G. Hermann, Draconis Stratonicensis liber de metris poeticis, Ioannis Tzetzae Exegesis in Homeri Iliadem (Leipzig 1812) and L. Bachmann, Scholia in Homeri Iliadem (Leipzig 1835).

3) Reviews by Hermant, Byzantion 53 (1983), 383-5; Bodson, AC 52 (1983), 289-90; Coulic, LEC 52 (1984), 172; Snipes, CR 36 (1986), 179-80 (none of them containing any detailed criticism). Extensive criticism and proposals for correction

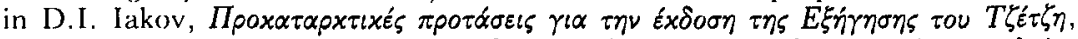

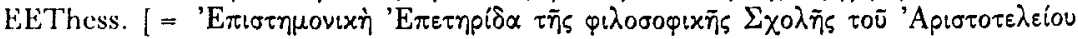

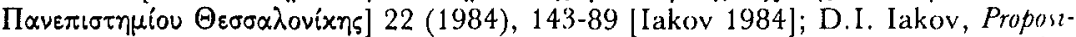

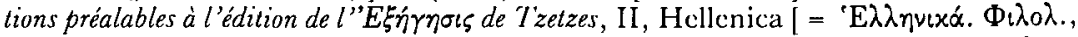

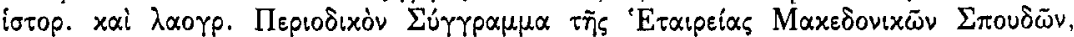
Thessaloniki, Bas. Sophias 2] 36 (1985), 27-77 [Iakov 1985]. Unfortunately, I have been unable to find $\mathrm{M}$. Papathomopoulos, Pour une nouvelle édition de l'Exégèse à l'lliade de Jean T'zetzès, Dodone 16 (1987) no. 2 (Philol.), 193-204 (sce l'Année philologique 1988, no. 2733).

4) In fact I think a new collation of the MS will eventually be imperative. Prof S.R. Slings collated p. 11-13 of Lolos' edition with the photograph provided on p. 216 and 217 and found a great many divergences from the report by Lolos. 
sive list of emendations proposed by Iakov. A list of small corrections follows at the end. Quotations are by page and line of Lolos' edition.

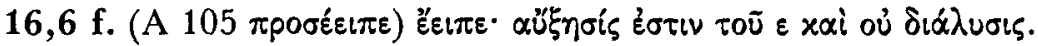

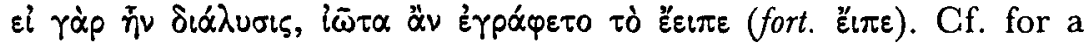

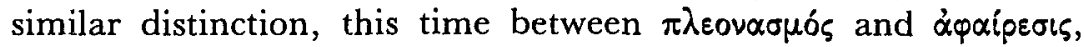
Apoll. Dyscolus Adv., Gramm. Gr. II i $147,11 \mathrm{f}$. with the commentary a.l. by Schneider. Tzetzes makes a distinction between $\alpha u ̈ \xi \eta \sigma \iota s$

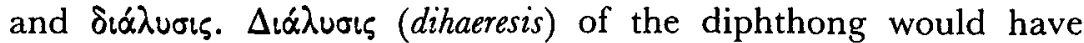

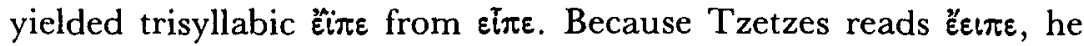
concludes that the first $\varepsilon$ must be an $\alpha \xi_{\eta} \eta \sigma \iota \zeta$. In this context it is virtually impossible to make out with certainty whether Tzetzes considered the $\varepsilon$ as an augment (which he might well, considering the fact that the form ei $\pi \varepsilon v$ has no recognizable augment when opposed to subjunctive $\varepsilon i \hbar \eta$, for instance), or as a pleonastic addition, the $\varepsilon$ duplicating the one contained in the first syllable of $\varepsilon i \pi \varepsilon v$. Apollonius Dyscolus regards the first $\varepsilon$ in $\varepsilon^{*} \varepsilon i \pi \varepsilon \nu$ (and in $\varepsilon \omega \rho \omega \nu$ or $\varepsilon$ हnxєv) as pleonastic, on the ground that the word still begins with a vowel after removal of the $\varepsilon$ (as against $\varphi \tilde{\eta}$ or $\beta \tilde{\eta}$, where the $\varepsilon$ belongs to the original, complete forms; in those cases its removal constitutes the pathos of aphaeresis). Although Apollonius does not

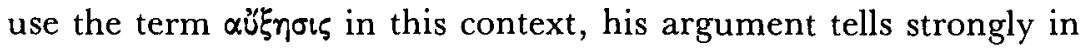

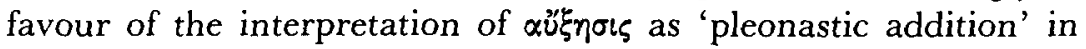
Tzetzes $^{5}$ ). And although $\alpha u ̈ \xi \eta \sigma \varsigma s$ is the normal terminus technicus for augment too, there is no reason why it could not be used in a laxer sense as well $\left.{ }^{6}\right)$. However, it seems that the whole point of the exact reference of $\alpha$ úknoเs is quite secondary to Tzetzes, who is not arguing about the status of the $\varepsilon$, but rather about the fact that it cannot have originated in a resolution of the diphthong $\varepsilon$.

5) The closest linguistic parallel from Apollonius is Pron., Gramm. Gr. II i

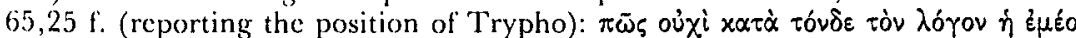

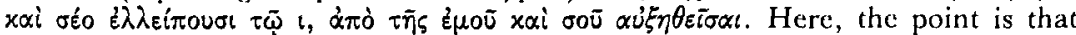
genitives with a diphthong in dihaeresi are mostly compensated in length (c.g. the

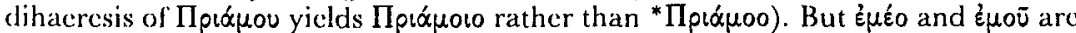

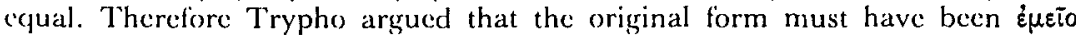

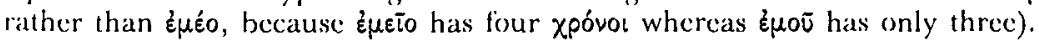

6) V.B. Botas, Dicionario de Terminología gramatical griega (Salamanca 1985), s.v.

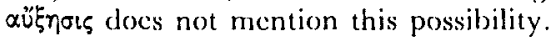




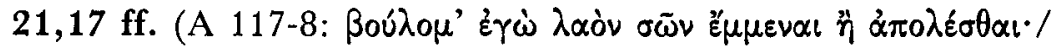

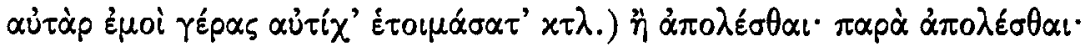

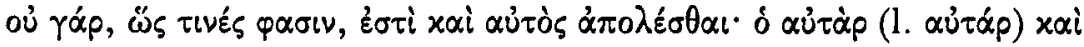

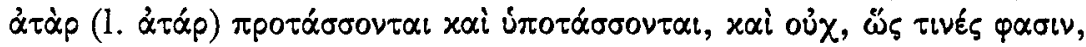

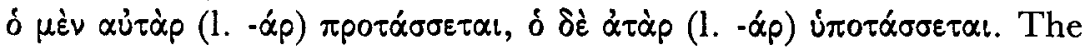
ed. failed to see that two separate lemmata are fused here, the first

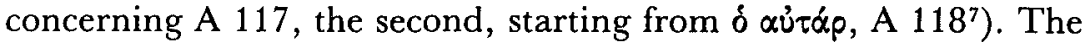
first remark reflects the discussion about the precise function of $\ddot{\eta}$

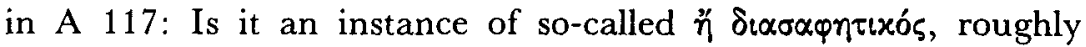
equivalent to $\mu \tilde{\alpha} \lambda \lambda$ ov $\left.\ddot{\eta} ?^{8}\right)$ Or do we have to do with $\ddot{\eta}$ $\pi \alpha p \alpha \delta\llcorner\alpha \zeta \varepsilon u x \tau \iota x o ́ s ?$ In that case it can be paraphrased by means of $x \alpha i$, since it does not introduce an absolute disjunction, but rather another possibility. See for this discussion Apoll. Dyscolus Coni., Gram.Gr. II i 221,16 ff. Tzetzes decides in favour of the first solution and glosses by means of $\pi \alpha p \alpha$, see LSJ s.v. C I 7: $\pi \alpha \rho \alpha$ is used here like quam after a comparative in Latin, 'in comparison with'.

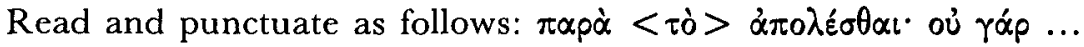

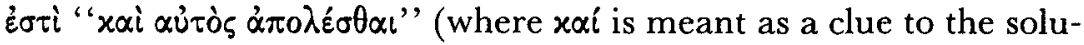

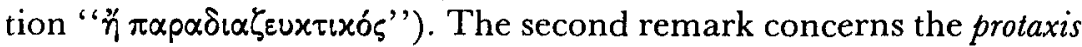

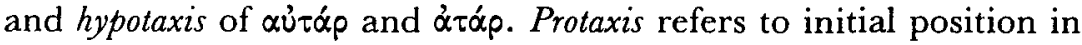
a complete sentence or a position in the first colon when one is deal-

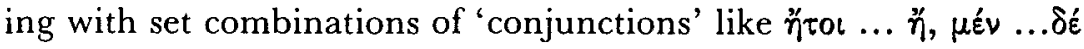
(cf. Apoll. Dyscolus Synt., Gramm.Gr. II ii 437,6 ó h̆

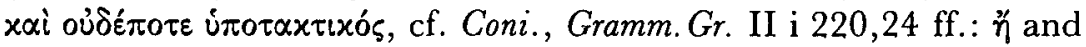

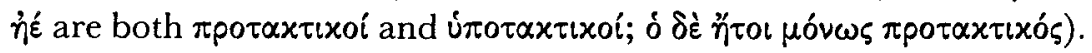
Tzetzes alludes to the theory that $\alpha$ ứa is sentence-initial, whereas $\dot{\alpha} \tau \alpha \dot{\rho}$ would be equivalent to $\delta \dot{\varepsilon}$, and would thus come in the second of two $\lambda$ ó identify the source of this theory. Usually, $\alpha \dot{\tau} \tau \dot{\alpha} \rho$ and $\alpha \tau \alpha \dot{\alpha}$ are lumped together as complete synonyms, and this is in fact the upshot of Tzetzes' discussion. Cf. Etym. M. 172,16 ff. and e.g. Scholia in Dion. Thrac. 285,5 ff.

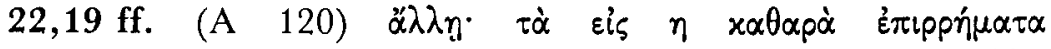

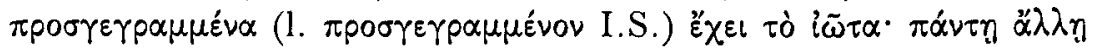

7) See for a list of similar cases, Iakov 1985, $67 \mathrm{ft}$.

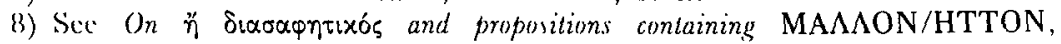
Mnemosyne 41 (1988), 46-66. 


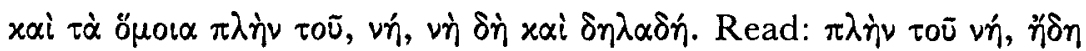

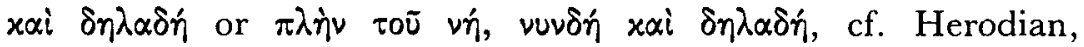
Gramm.Gr. III i 489,6 ff. The use of $\alpha \alpha \theta \alpha p \alpha$ is a bit disturbing here.

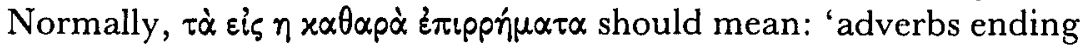
in vowel $+\eta$ ', which is clearly inappropriate here. A syllable or a letter is called $x \alpha \theta \alpha \rho o ́ \zeta$ if it is preceded by a vowel. If an $\eta$ is $x \alpha \theta \alpha \rho o ́ \varsigma$, it is automatically syllable-initial, since two vowels are separated by syllable-boundary. In theory, a $x \alpha \theta \alpha \rho o ́ \zeta$ syllable could consist of just one vowel, which is neither preceded nor followed by any consonants. I suppose Tzetzes might accordingly have reinterpreted the term to mean 'adverbs ending in $\eta$, not followed by any consonants', but I have no parallel to offer. Otherwise, we have to assume some deeper-lying corruption. Cf. Herodian, Gramm.Gr. III i 489,10 ff. $\left.{ }^{9}\right)$.

23,6 ff. (A 121 s.v. 'A $\chi\llcorner\lambda \lambda \varepsilon \cup$ б; the question is the spelling, either

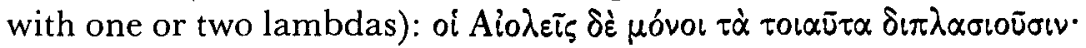

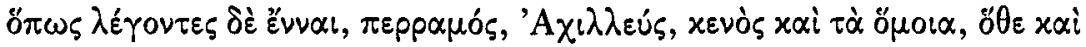

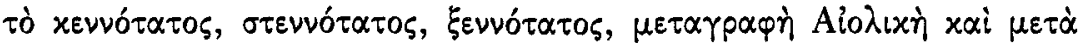

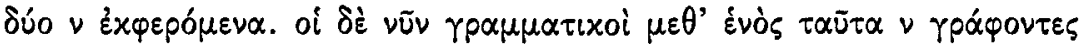

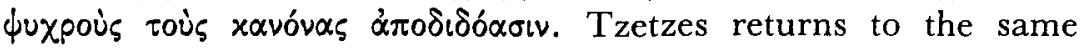

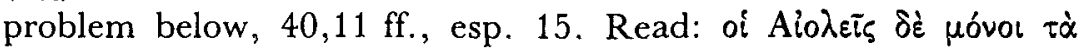

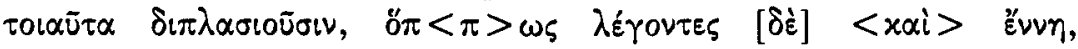

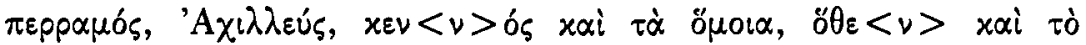

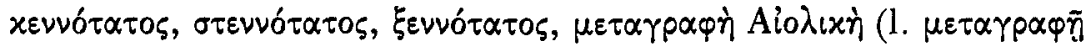

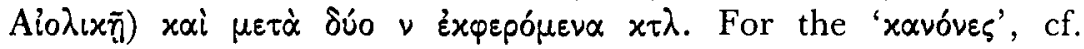
Greg.Cor. Dial. p. 610 S.; Etym. M. 582,44 ff.; Tzetzes' Scholia in Anecd. Oxon. Cramer 3,356,18. A different opinion is stated by Choerob. in Anecd. Oxon. Cramer 2,242; cf. Hdn. Gramm. Gr. III ii 302. See further Schwyzer I 683,4. "Evvn (adduced also by Greg. Cor. and Etym. M. 582,49) is thought to represent the name of the city on Sicily by Greg. Cor. The Etym.M. derives it correctly from $\nu \tilde{\omega}=\nu \dot{n} \theta \omega$. It is the imperfect ( 3 sing.) of $v \bar{\omega}$ 'to spin' (stem $v \eta$-). The Etym. M. mentions Herodian as the author of this view $\left.{ }^{10}\right)$. For

9) On the strength of ibid. $489,1 \mathrm{f}$. maybe $x \alpha \theta \alpha \rho \alpha$ should be emended to

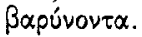

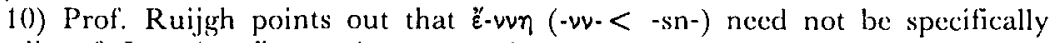
Acolic, cf. Ion.-Att. Ё-ppeov (-pp- < -sr-). 


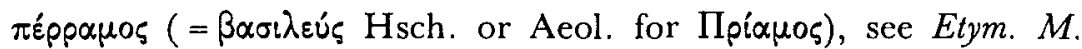
665,39 .

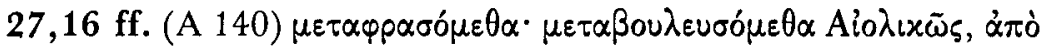

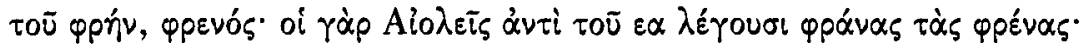

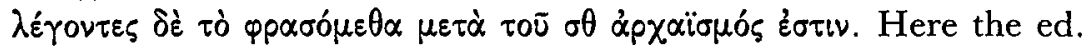
has unnecessarily complicated matters by inverting the MS order

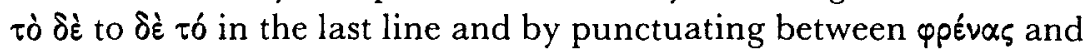

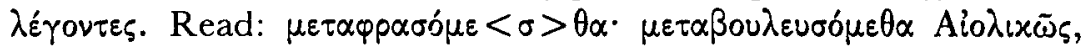

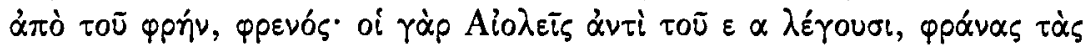

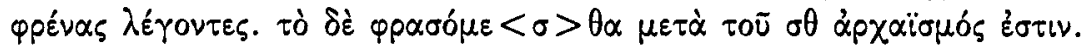

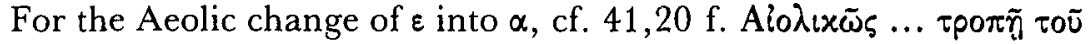
$\varepsilon$ eic $\alpha$. Maybe this canon was meant to cover the archaic dative

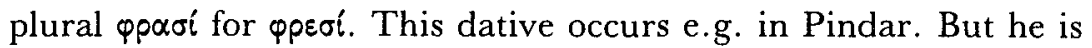
no model of Aeolic for ancient grammarians. In principle both dative $\varphi p \alpha \sigma i$ and accusative $\varphi p \alpha \dot{v} \alpha \varsigma$ are theoretically possible for Aeolic, although the accusative form is completely unattested $\left.{ }^{11}\right)$. I have not found the example $\varphi \rho \alpha \dot{v} \nu \alpha \varsigma-\varphi \rho \varepsilon^{\prime} \nu \alpha \varsigma$ elsewhere.

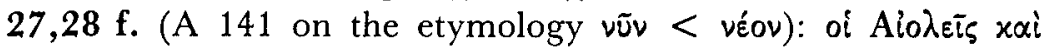

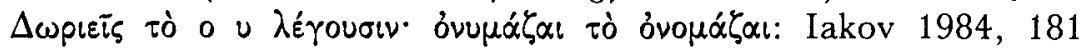
wrongly reads $\delta v o \mu \alpha \dot{\alpha} \zeta \in \iota v$ for $\delta v 0 \mu \alpha \dot{\alpha}\langle\alpha$, thus obscuring the point of the example which is meant precisely to illustrate the Acolic use of $u$

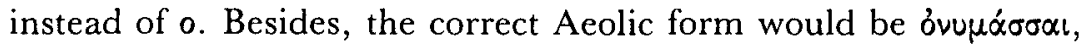
Doric $\delta v u \mu \alpha \dot{\xi} \xi \alpha$. Since corruption of $\xi$ to $\zeta$ is easier, I propose

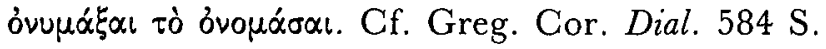

$31,25 \mathrm{f}$. (A 151 s.v. $\alpha \nu \delta \rho \alpha \sigma l v$; a note on the five meanings of

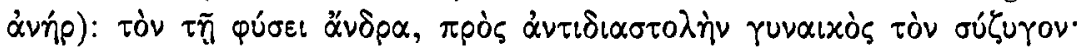

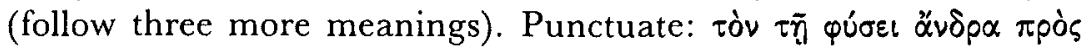

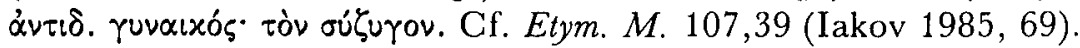

40,11 ff. (A 186; once more on the Aeolic habit of doubling con-

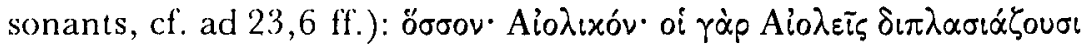

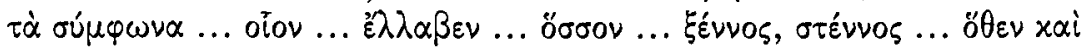

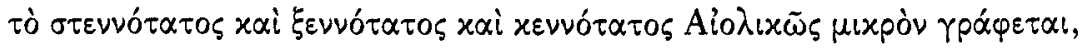

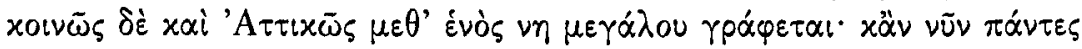

11) Фpaoi is, of course, the 'regular' form. The gen. plur. must originally have

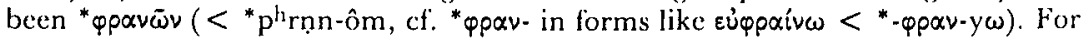

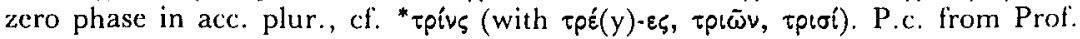
Ruijgh. 


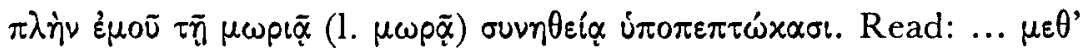

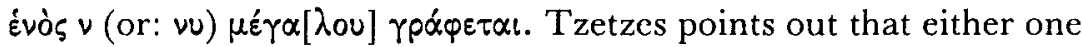
spells with one $n y$ and omega, or with double ny and omikron. Implicitly he rejects the canones provided by Chocroboscus (Gramm. $G r$. IV ii 76) which are here identified with the $\mu \omega \rho \dot{\alpha}$ ouvin $\theta \varepsilon เ \alpha$.

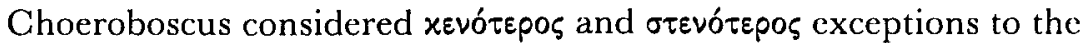
rule requiring - $\dot{\omega} \tau \varepsilon p o \varsigma$ after a short syllable. He explains this excep-

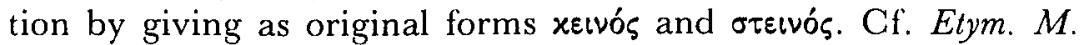
275,50 (where see also the annotations for Moschopulos' defense of

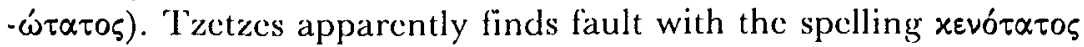
and takes $x \in v \omega \tau \alpha \tau o \varsigma$ to be the correct form. He adds, though not

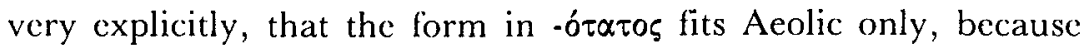
there the double consonants invalidate the basic rule. Of course, o and $\omega$ were pronounced the same way in Tzetzes' day.

44,5 f. (A 194; on the allegorical interpretations of the goddess Athena and her epithets. Athena is explained as an allegorical symbol for the thick air (ánp) close to the carth, and for the moon

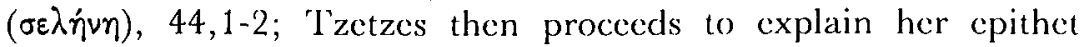

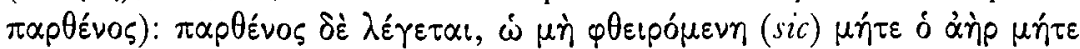
$\dot{\eta} \sigma \varepsilon \lambda \dot{\eta} \sim \eta$ : Rcad: $\dot{\omega} \zeta \mu \dot{\eta} \varphi \theta \varepsilon i \rho o ́ \mu \varepsilon v o t ~ x \tau \lambda$.

45,29 ff. Another highly allegorical passage: Tzetzes is explaining A 194-5, where Athena is sent down by Hera to calm Achilles. White-armed Hera stands for Achilles' soul, envisaging pure ('white') action. Athena stands for Achilles' rational capacitics. 'Thus, what happens is that Achilles' pure soul stimulates his

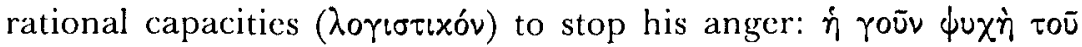

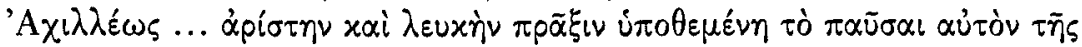

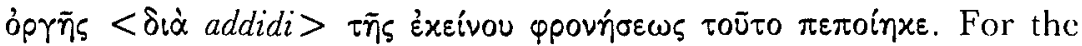

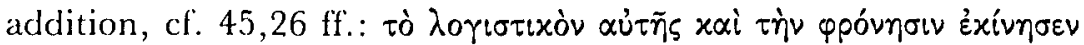

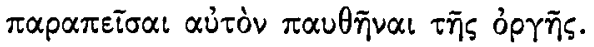

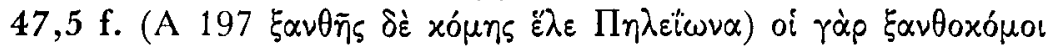

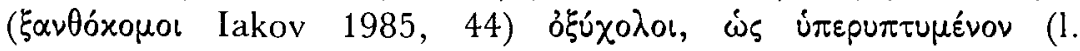

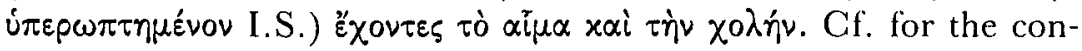

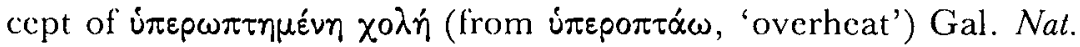
Fac. 16, 512 Kühn. See further Iakov 1984, 161 a.l.

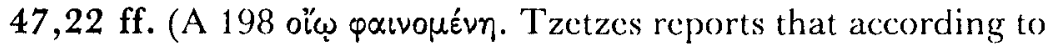
some only Achilles and Socrates had visions of their particular

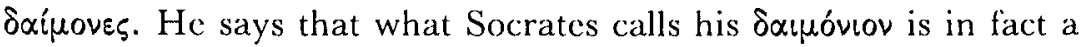


manifestation of the prognostic faculty of his own soul): $x \alpha \tau \dot{\alpha} \gamma \dot{\alpha} \rho$

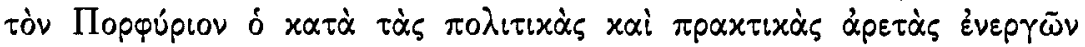

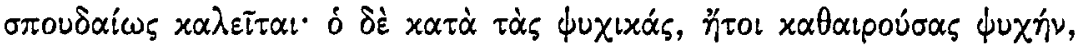

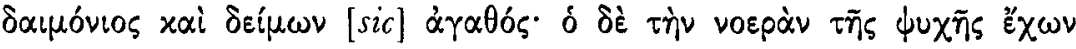

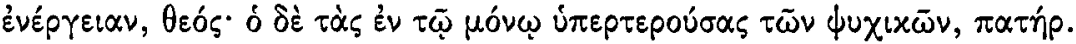
Tzetzes refers to Porphyry's Sententiae ad intelligibilia ducentes $32,90 \mathrm{ff}$. (ed. E. Lamberz); a quick comparison eliminates most of the problems of our passage. Porphyry's text runs: $\delta$ iò $x \alpha i$ o $\mu \varepsilon \dot{v} v \alpha \tau \dot{\alpha}$

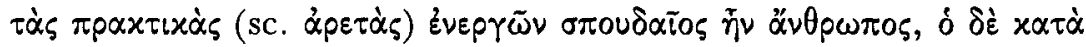

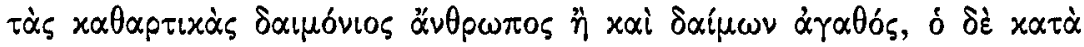

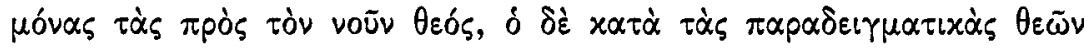
$\pi \alpha \tau \eta \dot{p}$. Accordingly, emend the Tzetzes-passage as follows: ó $x \alpha \tau \dot{\alpha}$

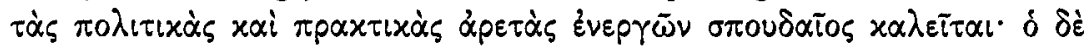

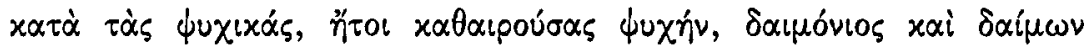

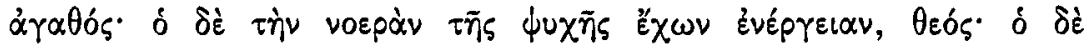

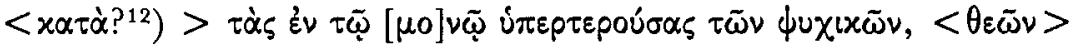
$\pi \alpha \tau$ p. Cf. for the last part of the sentence Porph. ibid. 32,63 ff.:

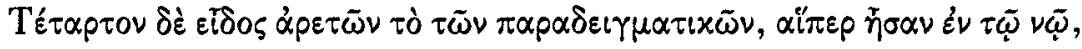

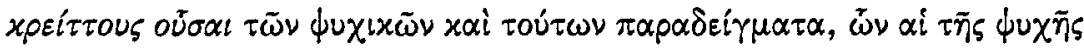
$\tilde{\eta} \sigma \alpha \nu \delta \mu o t \omega \mu \alpha \tau \alpha$. Porphyry is here describing the two pairs of virtues, the highest belonging to the voũs, the lower ones to the $\psi u x \dot{\eta}$.

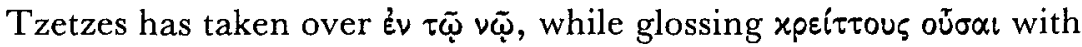

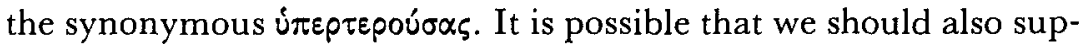

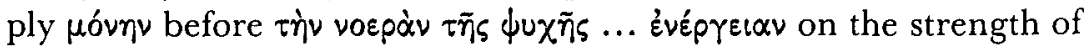

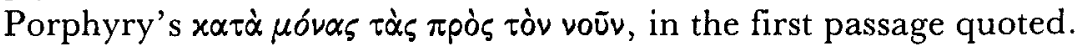
One can easily imagine that this word, once it had dropped out, got inserted in the wrong place (namely after $\tau \tilde{\omega} \nu \tilde{\omega})$; afterwards, $\dot{\varepsilon} \nu \tau \tilde{\omega}$ $\nu \tilde{\omega} \mu o^{\prime} v \omega$ was changed into $\varepsilon^{\nu} \tau \bar{\omega} \mu o ́ v \omega$ by haplography. See on this passage also Iakov 1984, 161.

48,26 f. (A 200) Etymologies are provided for Athena's second name, 'Pallas': It is suggested that this name derives from $\pi \alpha \dot{\alpha} \lambda \omega$. Athena 'brandishes', or 'shakes' the heart of Dionysus, after he was

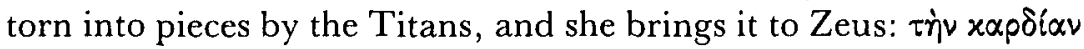

12 The change of construction complicates matters somewhat. Tzetzes may

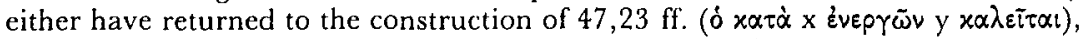

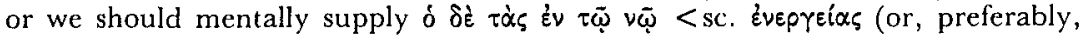

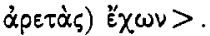




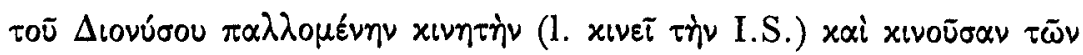

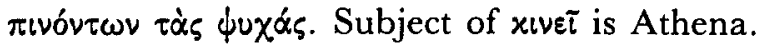

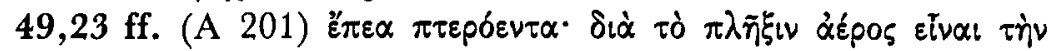

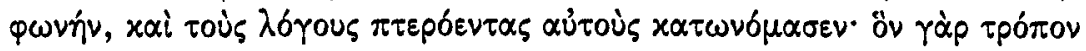

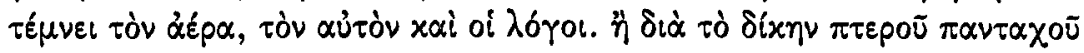

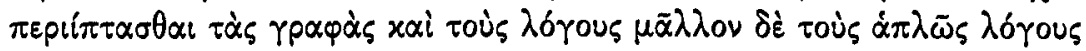

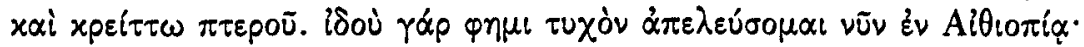

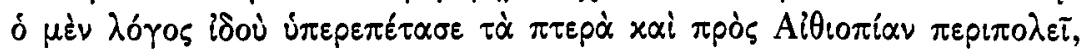

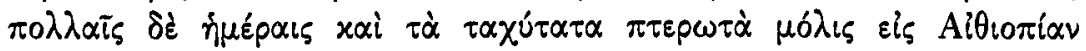

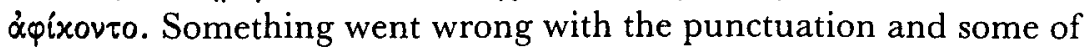
the constituents seem to have been interchanged. I propose: है $\pi \varepsilon \alpha$

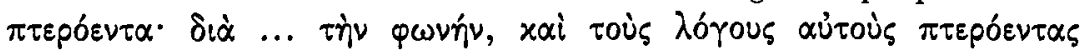

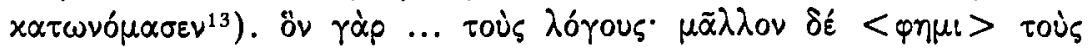

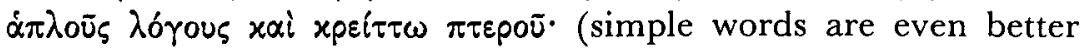

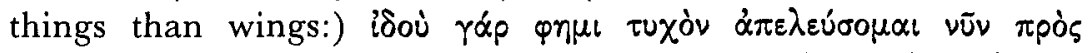

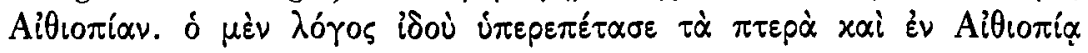

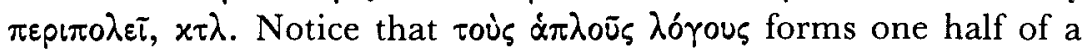
double opposition. On the one hand 'simple words' are better then rpopai, on the other they surpass even physical wings in 'wingedness' and agility. The general idea is that $\lambda$ ó $o \zeta$, as the verbal expression of a mental process, can find instantaneous, if

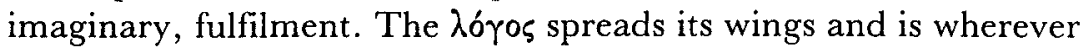
it likes immediately. The passage is reminiscent of Hom. Il. O

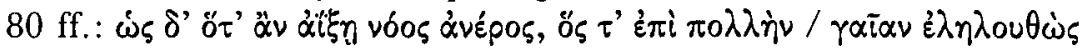

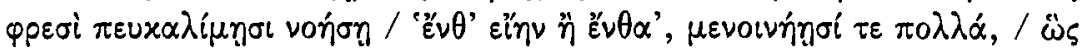

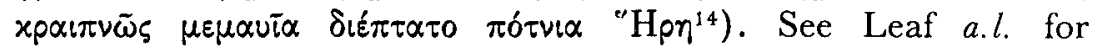
references.

54,9 ff. (A 216-9) See the separate note in this same volume ('Tzetzes on a Mini-Thesis ...').

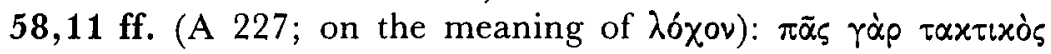

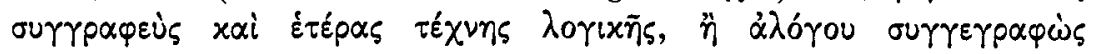

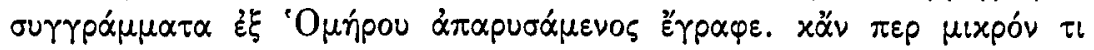

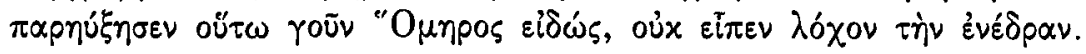

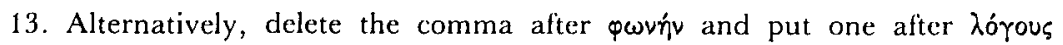
instead. However, this somewhat disturbs the comparison between $\varphi \omega v \dot{\eta}$ and $\lambda \dot{o}$ yol that is worked out in the next sentence.

14) I owe this reference to Prof. Ruijgh. 


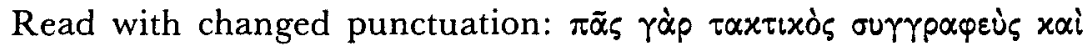

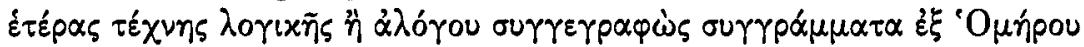

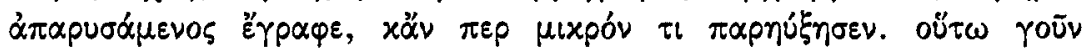

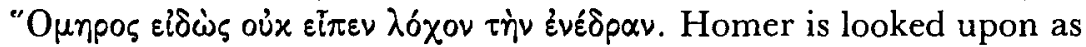
the encyclopedic source of all knowledge here, just as in the tract de vita et poesi Homeri II, by pseudo-Plutarch (where $\S 192 \mathrm{ff}$. deal with Homerus' strategic knowledge). Our passage means: 'For every writer on strategy and every composer of treatises on any other rational or irrational art wrote them taking his cue from Homer, even if he amplified things a bit. Therefore, since Homer was knowledgeable on the subject, he did not use $\lambda$ ó $_{0} \varsigma$ to indicate an ambush'.

58,25 ff. (On A 226-7, Achilles reproaching Agamemnon with

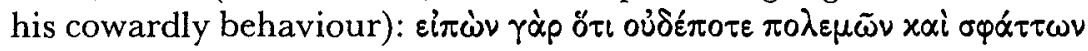

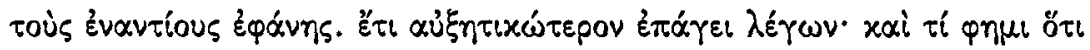

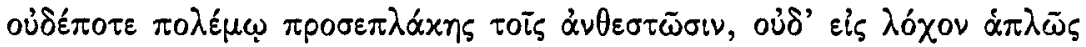

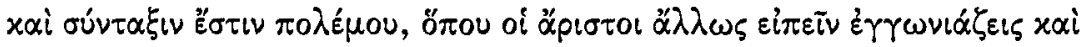

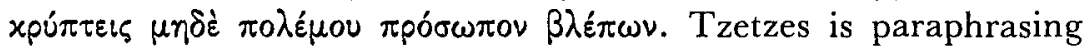
Achilles' meaning. Here, too, the punctuation is misleading; read:

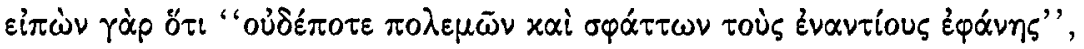

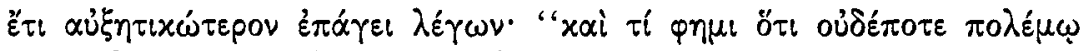

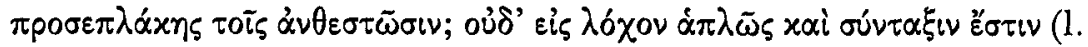

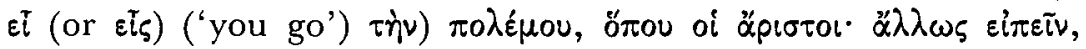

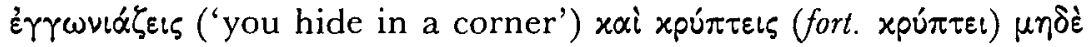

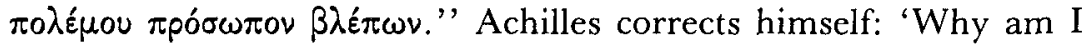
saying that you do not fight? You do not even take the trouble of going to your post in the order of battle!'

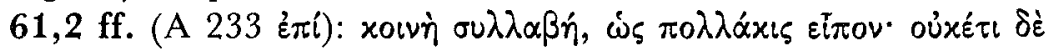

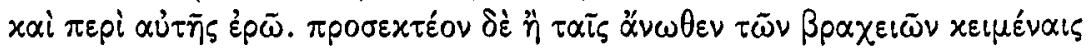

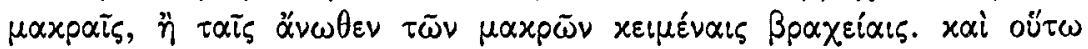

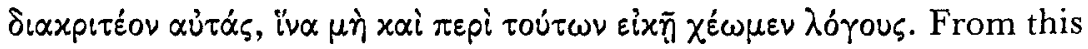
note it appears that Tzetzes indicated irregular syllable-lengths in the small blocks of text preceding the notes, and possibly in the lemmata too. Ed. has not done this (e.g. in 59,16 , to which the note on $61,2 \mathrm{ff}$. refers).

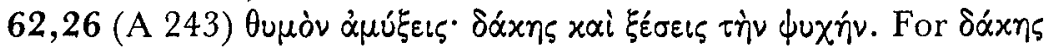
one would expect a 2 sing. indicative, preferably future tense in

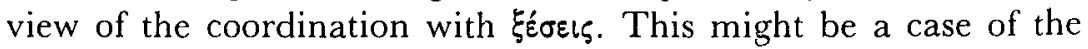


aorist subjunctive being used instead of a future, cf. S.B. Psaltes, Grammatik der Byzantinischen Chroniken (Göttingen 1974), 217 f. In that case read $\delta \alpha x n s$. Otherwise, the easiest emendation seems ind. fut. pass. 2 sing. $\delta \alpha x \eta$ os (a late Greek equivalent for Attic $\delta \eta \chi \theta \dot{\eta} \sigma \varepsilon$ ), cf. Aretae. 60 (Ed. Oxon. (=SD 2.2)) (see W. Veitch, Greek Verbs irregular and defective (Oxford 1879), 163). However, this has the disadvantage of creating a slight zeugma, since tiेv $\psi u \times \dot{\eta} v$ then has a different syntactic function with each of the two verb-

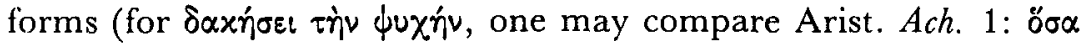

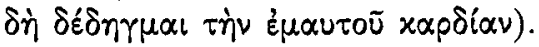

64,25 ff. (Analysing the praise of Nestor, A $247 \mathrm{ff}$., esp. 250-2; according to Pindar, the highest praise is to say that someone is (or

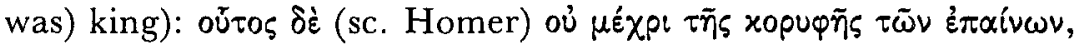

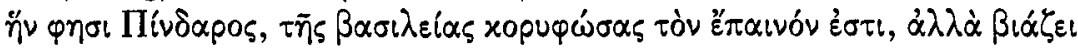

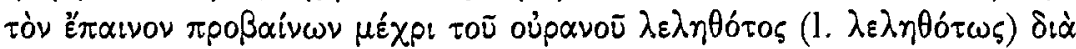

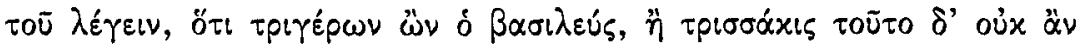

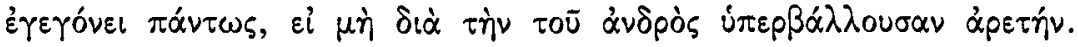
Homer does not stop short at the highest praise, but he goes one

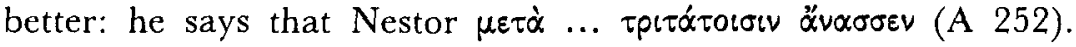

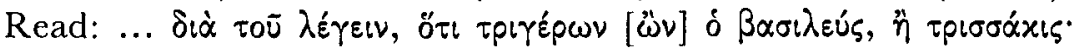

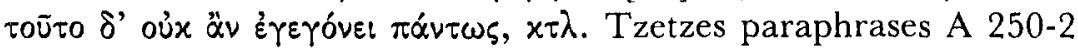

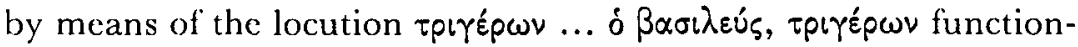
ing as predicate: Nestor ruled over two generations and is now king

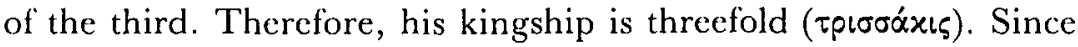

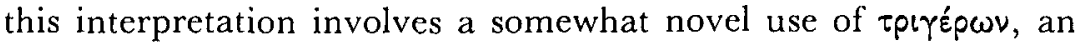

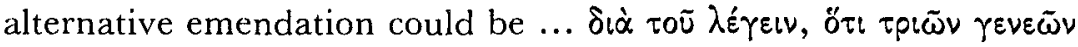
$\delta \beta \alpha \sigma i \lambda \varepsilon u ́ \varsigma, \ddot{n} \tau \rho ı \sigma \alpha \alpha x ı \varsigma x \tau \lambda$.

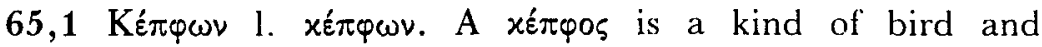
metaphorically a 'feather-brained fellow' (LSJ s.v.), cf. Aristoph.

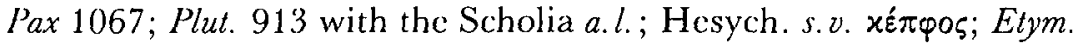
M. s.v. 504,1 f.; Suda I 3,96 ff. (Adler) s.v.

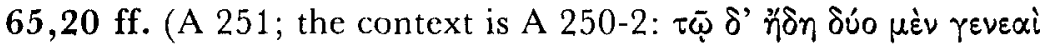

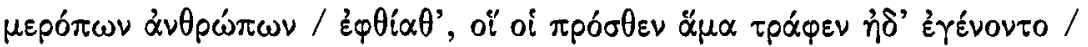

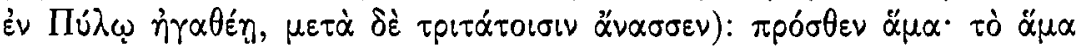

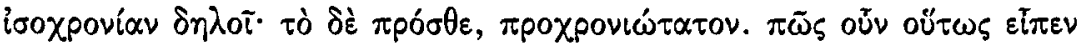

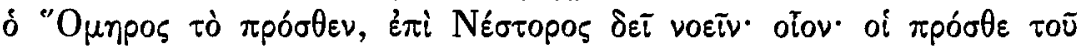

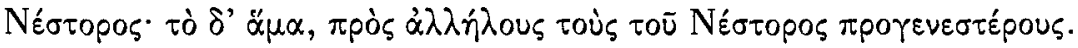

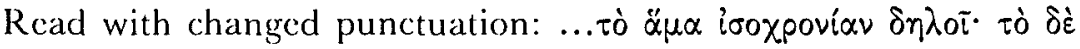




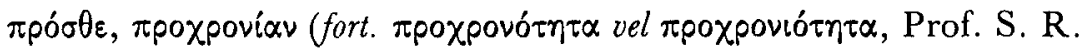

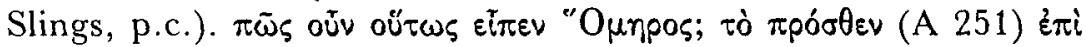

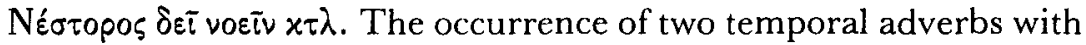
incompatible meanings in the same sentence calls for some elucidation. Therefore, Tzetzes discusses the differentia between the two. He connects $\pi \rho o ́ \sigma \theta \varepsilon \nu$ with oi: Homer is talking about people who were born and grew up before Nestor. "A $\mu \alpha$ is taken to refer to the mutual relationship of those people (leaving Nestor out of account): they were contemporaries of each other. Nowadays we would, of course, rather connect oi ... $\alpha \mu \alpha$ and separate $\pi p o ́ \sigma \theta \varepsilon v$ : 'Two generations of mortal men had he ere now seen pass away, who of old $(\pi \rho o ́ \sigma \theta \varepsilon v)$ had been born and reared with him (oi ... «ँ $\mu \alpha)$ ' (tr. Murray).

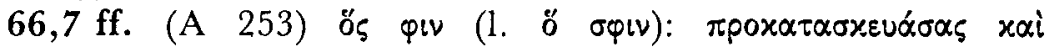

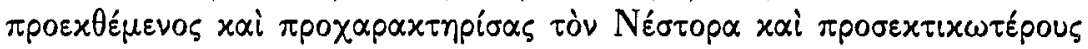

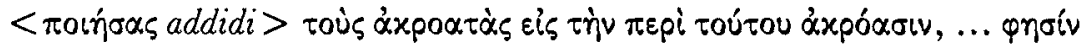
$x \tau \lambda$.

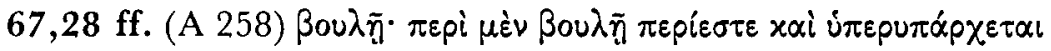

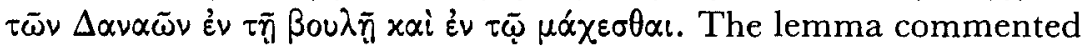

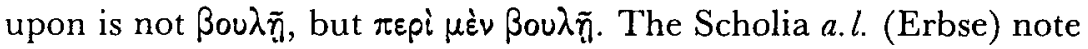
that $\pi \varepsilon p i$ either stands for $\dot{\pi} \pi \dot{p}$ or that one should take $\pi \varepsilon p i$... ह̇ $\sigma \tau \varepsilon$

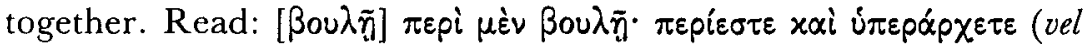
ن́ $\left.\pi \varepsilon p^{\prime} \chi \varepsilon \tau \varepsilon\right) \tau \tilde{\omega} \nu \Delta . \chi \tau \lambda$. For the emendation $\dot{\pi \varepsilon \rho \varepsilon \varepsilon \chi \varepsilon \tau \varepsilon, ~ c f . ~ t h e ~ S c h o l i a ~}$ a.l. in Anecd. Gr. Matranga 413,22.

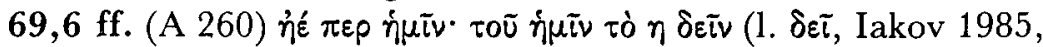

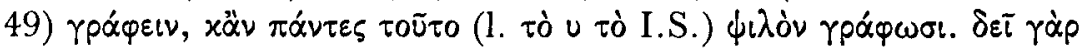

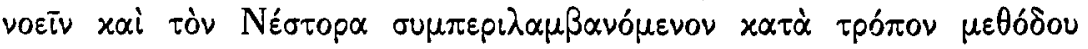

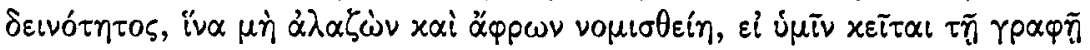

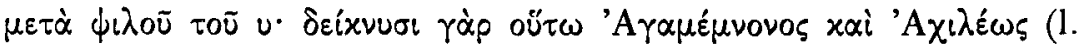

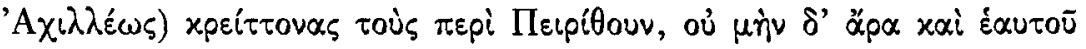

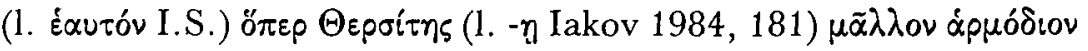

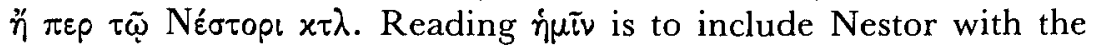

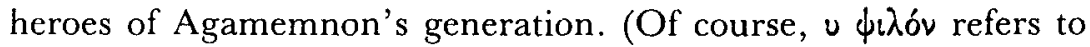
the name of the letter only). This reading is necessary, because it fits Nestor's rhetorical tactics: He wins his audience by not putting himself above them. This necessitates the further change of $\dot{\varepsilon} \alpha u \tau \bar{v}$ to Éautóv.

70,20-71,3 (On A 264, Kaเvéa): See Iakov 1984, 169 f. Kaineus 
in his arrogance demanded that divine honours be paid to his lance:

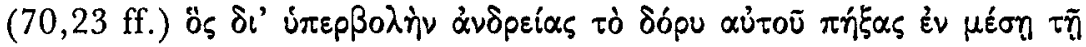

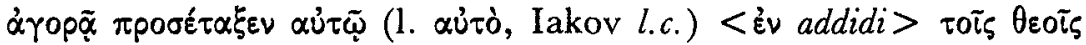
$\alpha p t \theta \mu \varepsilon i v$. Cf. the parallel passage in Eustath. I 158,28 ff. vdV.

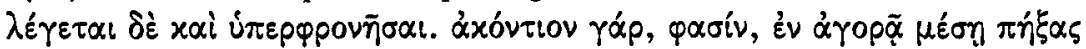

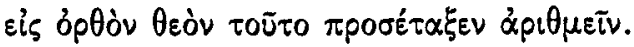

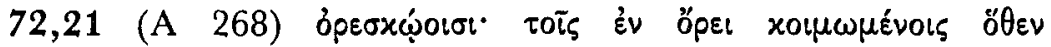

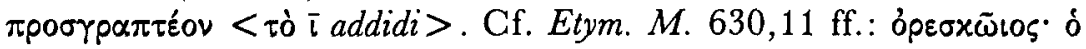

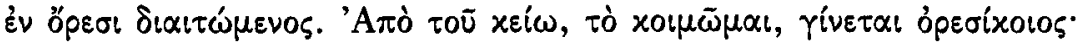

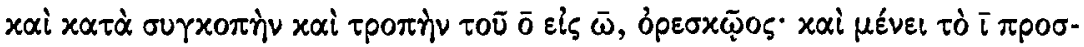

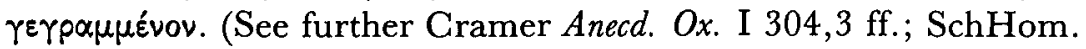
Il. A 268b.)

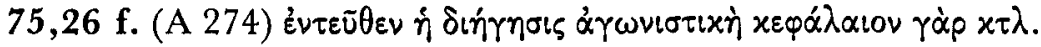
Punctuate between $\dot{\alpha} \gamma \omega \nu \iota \sigma \tau \iota x \eta ́$ and $x \varepsilon \varphi \alpha \dot{\lambda} \alpha \iota \nu$.

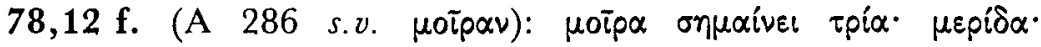

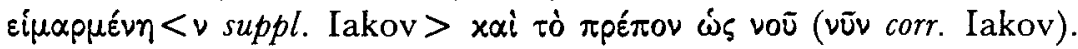
See Iakov 1985, 50. Add the parallel Etym. M. 589,21 ff., esp. 589,33 .

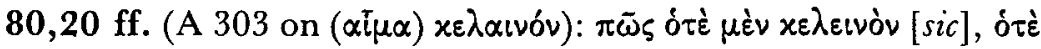

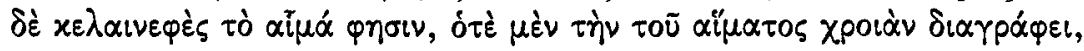

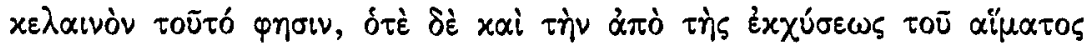

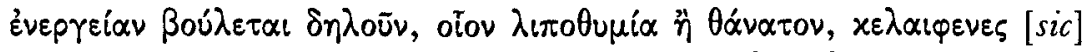

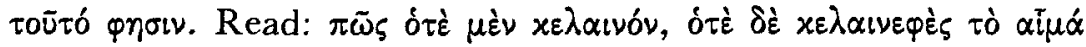

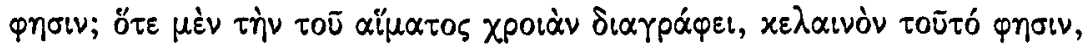

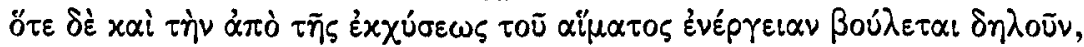

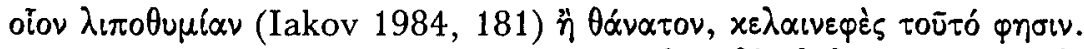

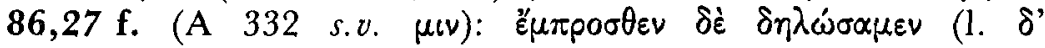

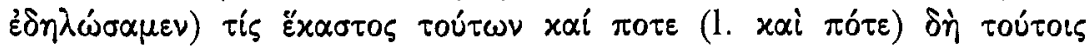

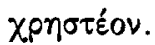

97,19 ff. This passage concerns Achilles' appeal to Thetis, A $352 \mathrm{ff}$, and her advise to him. Tzetzes classifies Achilles' speech as belonging to the révos sixavixóv, even though he admits that Thetis' reply should rather be considered $\sigma u \mu \beta 0 u \lambda \varepsilon u \tau \iota x o ́ v(97,26-98,2)$. He

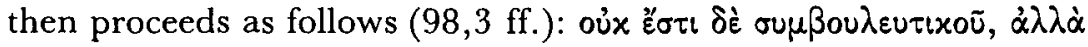

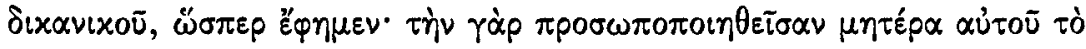

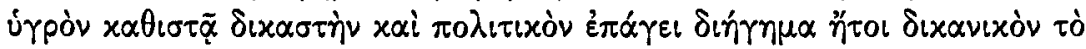

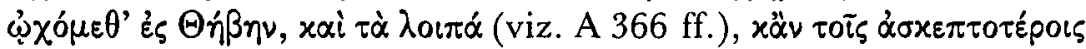

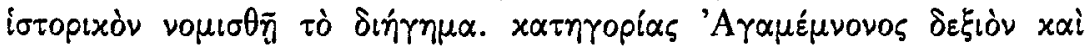




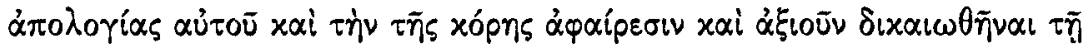

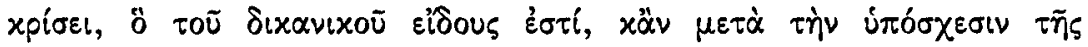

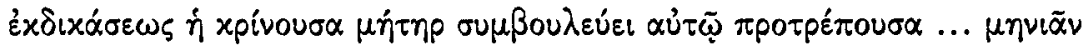

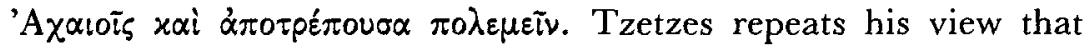
Achilles' speech to Thetis does not belong to the genus deliberatioum but to the genus iudiciale. Its forensic character appears from the accusations it contains, plus the self-defense and the request to pass

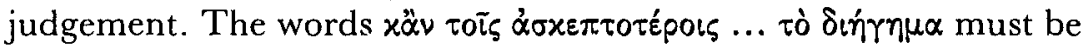
considered a parenthesis. Read with change of punctuation: ...( $x \ddot{\alpha} \nu$

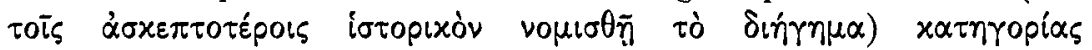

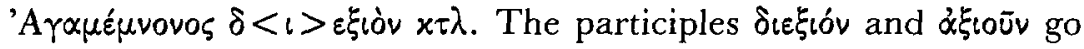

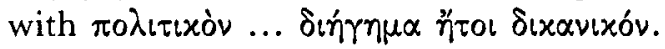

99,25 (A 358; Tzetzes is commenting on seagods metonymically representing 'water', and supports his discussion with etymolo-

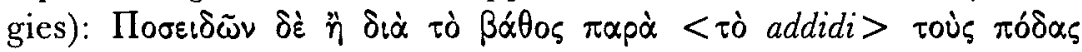

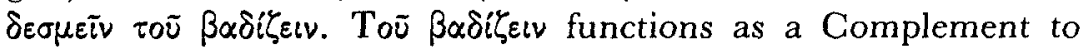

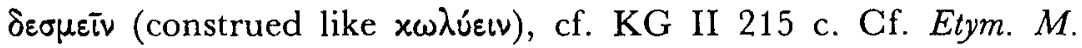

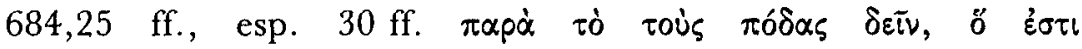

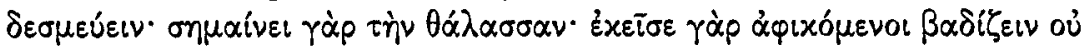
$\delta u v \alpha \dot{\mu} \varepsilon \theta \alpha$. The passage from Etym. $M$. provides parallels for the other etymologies in our lines as well.

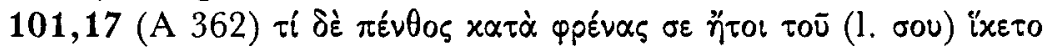
$x \alpha i \tilde{\eta} \lambda \theta \varepsilon$. The necessity of the emendation is apparent from the

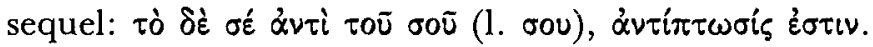

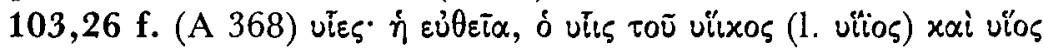
(1. vios). Cf. Herodian Gramm. Gr. III i 409,17 ff.; Etym. M. $775,20 \mathrm{ff}$. (where the forms are spelled with one iota). For the accent of utos, cf. Sch.Hom. O 138b; E 266al. An alternative is provided by Sch.Hom. E $216 \mathrm{a}^{2}$ üios.

106,22 ff. This paragraph is not, strictly speaking, part of the commentary on A 394, although it is printed as such by Lolos. Rather, a new section begins here, recapitulating Tzetzes' views on the allegorical signification of Thetis' parentage (cf. 92,10 ff.): $\tau 0 \tilde{u}$

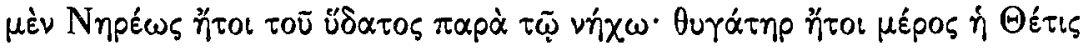

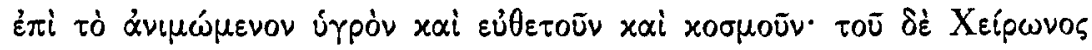

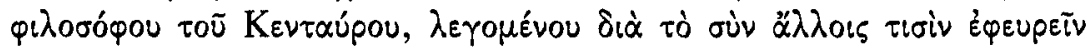

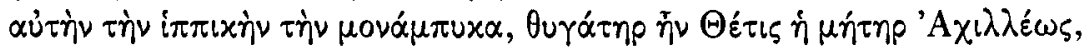

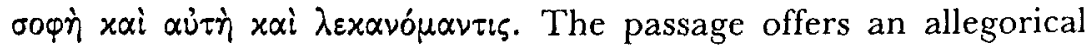


interpretation of 'Thetis' embassy to Zeus. The allegorical signification is introduced by ñ accounts of Thetis' parentage, each of which accounts for part of her (allegorical) essence: If she is said to be a daughter of Nereus, the soothing capacities of her (i.e. water's) damp evaporations are alluded to. And because she is wise and a 'dish-diviner', she is associated with the philosopher Cheiron (who is nicknamed 'Centaur' because he invented horse-riding). Mantic and philosophical qualities are indeed ascribed to Cheiron, see $R E$ III 2302-8 (Escher) s. $v$. Chiron. His knowledge of the future comes out in Eur. IA 1064; Hor. Epod. 13,11 ff.; Pind. Pyth. IX 52 f. He is known as a philosopher e.g. in Plut. de E apud Delphos 6. It is not difficult to imagine what being бoфทं and having a philosopher for a father have to do with each other. Nor is the relation between Cheiron's and Thetis' mantic capacities problematic in itself. But why is Thetis a $\lambda \varepsilon x \alpha \nu o ́ \mu \alpha \nu \tau \iota \zeta$ ? Tzetzes interprets the messages delivered by Thetis as if they were obtained through divination by means of water ( $\lambda \varepsilon x \alpha \nu o \mu \alpha \nu \tau \varepsilon i \alpha$ belongs to this genus): see 92,24 ff.; 112,23; 113,3; 113,27. For $\lambda \varepsilon x \alpha v o \mu \alpha \nu \tau \varepsilon i \alpha$ see A. Bouché-Leclerq, Histoire de la Divination dans l'Antiquité (Paris 1879-82 (New York 1975)), I $184 \mathrm{f}$. (quoting Psellus, De op. daem. p. 42); I 199; I 339-40; III 354. Read:

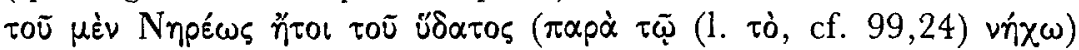

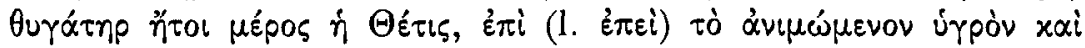

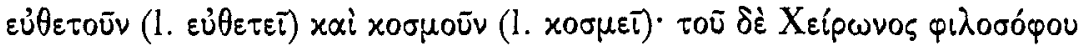

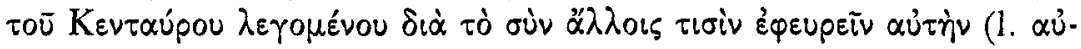

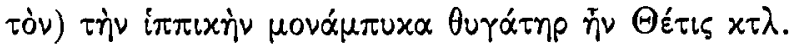

109,22 ff. (On A 407; however, $\tau \alpha \tilde{u} \tau \alpha$ refers to Achilles' version of the story of how Thetis had helped Zeus, A 397-406): $\tau \alpha \tilde{u} \tau \alpha \mu \varepsilon \dot{v}$,

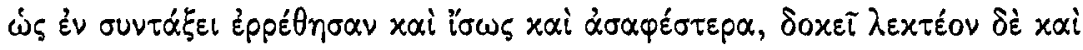

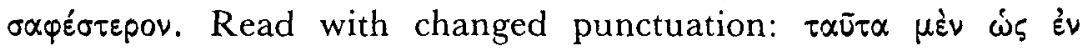

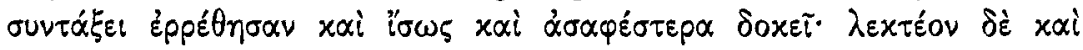

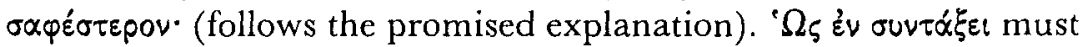
mean something like 'embedded in a (densely) composed story' here.

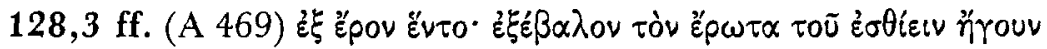

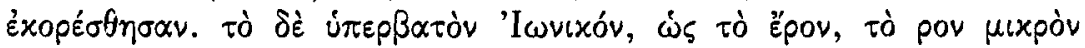

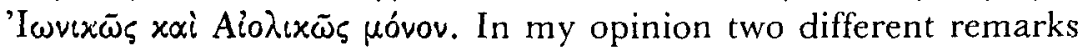
are merged here (see above, $\operatorname{ad} 21,17 \mathrm{ff}$.). The first one explains the 


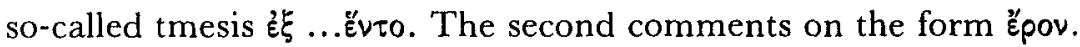

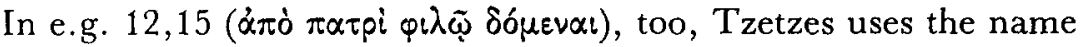

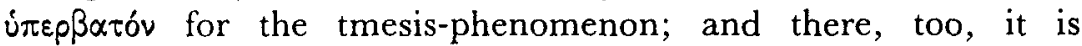
associated with Ionic; cf. 51,24; 86,1. Accordingly, we have to assume that an example has dropped out after $\dot{\omega}_{\varsigma}$ tò ... Read: $\dot{\varepsilon} \xi$

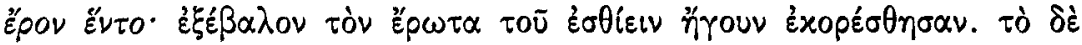

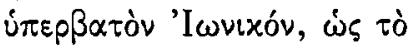

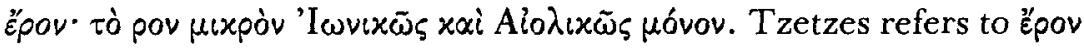
as opposed to Attic êpws with omega (plus their respective declensions). See further Iakov 1985, 63 who offers a different solution (he deletes $\dot{\omega} \varsigma$ and changes tó into roũ).

131,4 ff. Interesting for the sarcastic criticism directed against the famous grammarian Herodian. Herodian had deduced from A 483 that $x \varepsilon$ $\lambda_{\varepsilon \cup \theta 0 \varsigma}$ must necessarily refer to a journey by sea. For in this verse, the qualification irpar is omitted. Tzetzes proceeds as

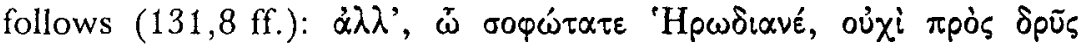

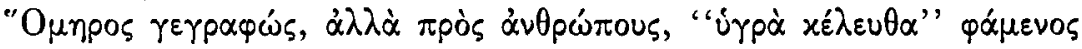

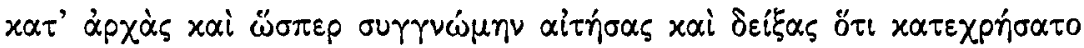

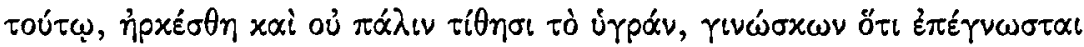

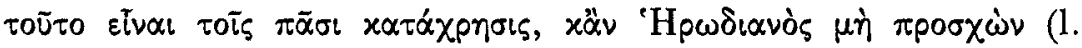

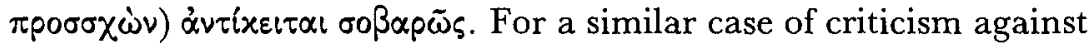

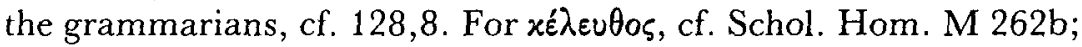
Etym. M. 502,21 ff. The opinion ascribed to Herodian is neither in the Scholia, nor in Gramm. Gr. III i/ii.

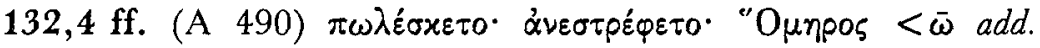

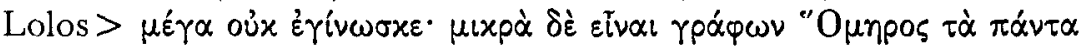

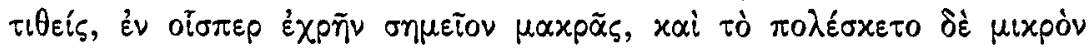

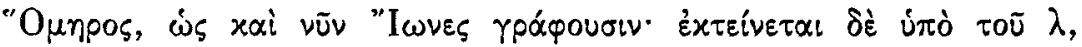

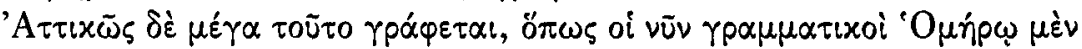

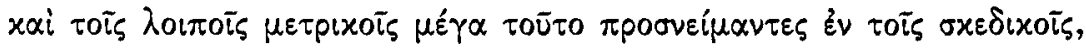

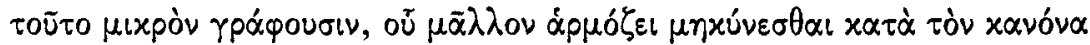

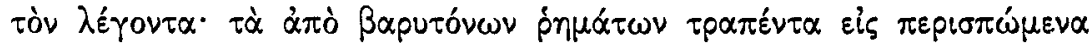

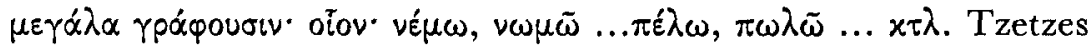
points out that since Homer did not distinguish $o$ and $\omega$ in writing, he always wrote $o$ and added a macron where necessary. Thus, he

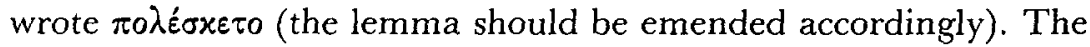
Ionians, too, write $\pi 0 \lambda \varepsilon \dot{\varepsilon} \approx \varepsilon \tau o$, but in Attic the word is spelled with $\omega$. The second part of 'Tzetzes' commentary again contains 
criticism of the grammarians, whose distribution of 0 and $\omega$ is completely perverse according to Tzetzes: they spell $\omega$ when editing Homer, but 0 in their schoolbooks, whereas there of all places $\omega$

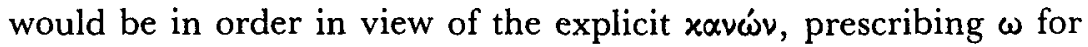
contract verbs derived from barytone ones. This criticism resembles the one in $128,6 \mathrm{ff}$. where the grammarians are reproached with drawing up perverse rules for the distribution of

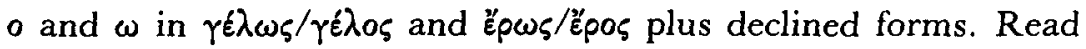

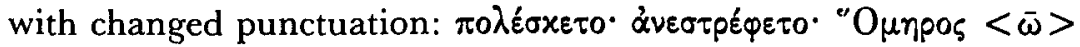

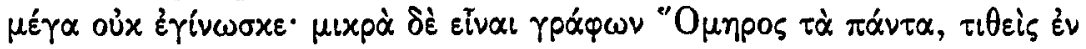

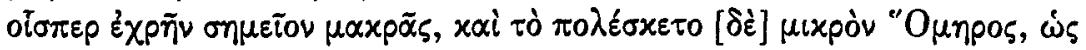

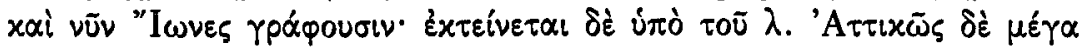

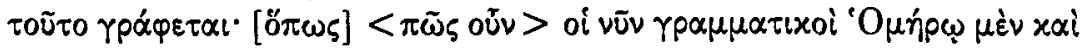

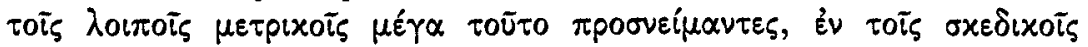

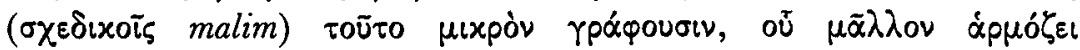
$\mu \eta x u ́ v e \sigma \theta \alpha \iota x \tau \lambda$. Cf. Iakov 1985, 64 and 69 (Etym. M. 583,4). Other relevant parallels for the spelling of $\pi 0 \lambda \varepsilon ́ \sigma x \varepsilon \tau 0 / \pi \omega \lambda \hat{\varepsilon} \sigma x \varepsilon \tau 0$ are: Etym.

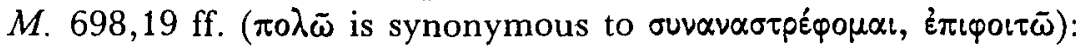

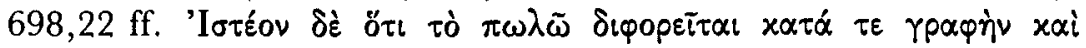

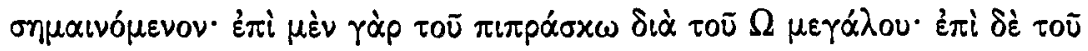

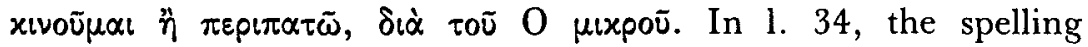

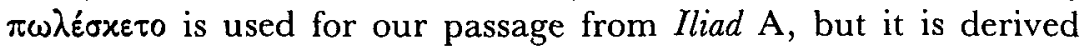
from $\pi 0 \lambda \bar{\omega}$. The lengthening of $O$ to $\Omega$ is called poetic (1. 38-9).

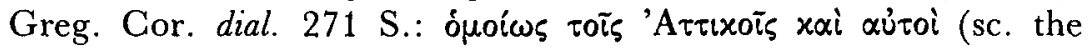

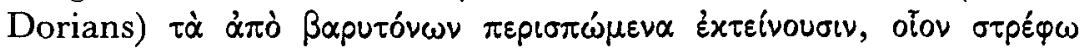

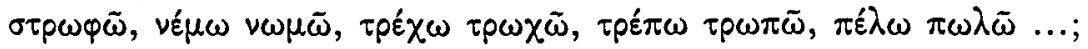
Herodian Gr.Gr III i 448,7 f. ( $\left.\pi 0 \lambda \bar{\omega}=\alpha^{2} v \alpha \sigma \tau \rho \varepsilon ́ \varphi o \mu \alpha l\right)$; Eustath. I

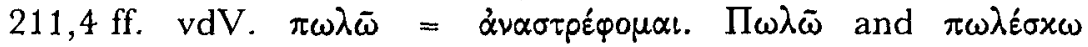

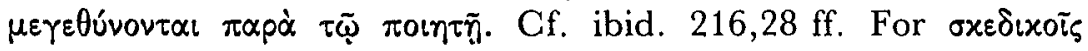
(which is not impossible, though $\sigma \chi \varepsilon \delta$ ixois may be preferred), see H. Hunger, Die hochsprachliche profane Literatur der Byzantiner (München 1978), Bnd. II p. 25 f. and n. 20.

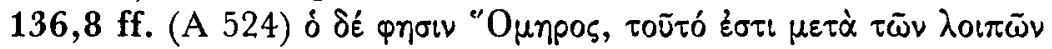

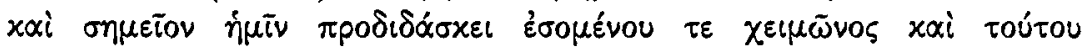

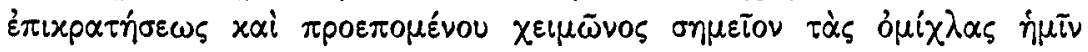

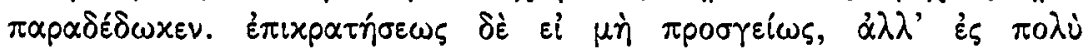

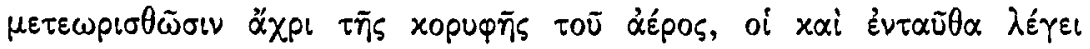
$\gamma \in v \varepsilon ́ \sigma \theta \alpha$. Tzetzes is dealing with A 524, Zeus' answer to Thetis. 
The actions of the gods are allegorically related to physical (meteorological) phenomena. As Tzetzes has already explained (133,13 ff.), Thetis represents moist vapours (oj $\mu^{\prime} \chi \lambda \eta \eta$; cf. A 359) emanating from the sea and filling $\alpha \dot{n} p$ ( = Zeus). The heavier parts of this fog embrace the lower regions of ànp, i.e. Zeus' knees, while its lighter elements soar up high into the air. Zeus' initial silence represents the uncertainty of the effects the fog will produce. But then a storm breaks out, which will eventually settle down again. In our passage, Tzetzes recapitulates this interpretation. Read with

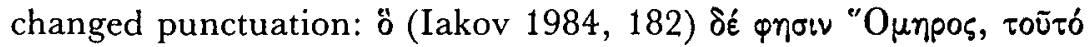

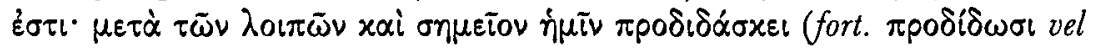

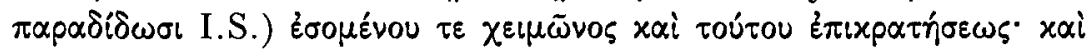

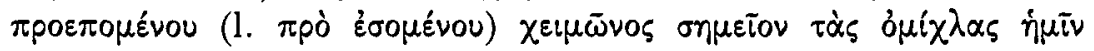

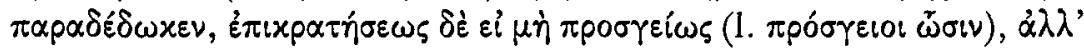

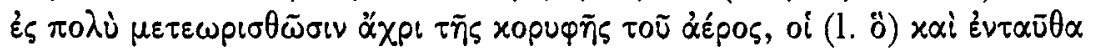

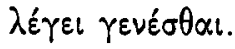

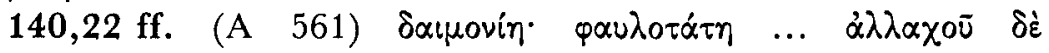

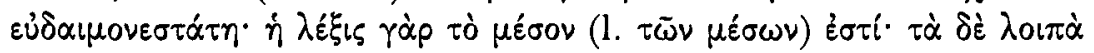

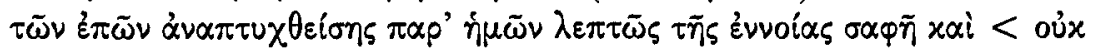

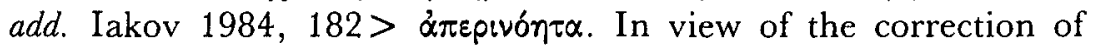

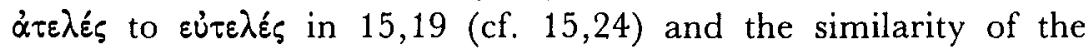

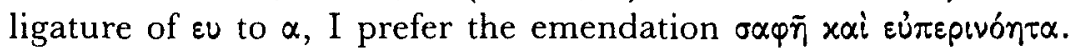

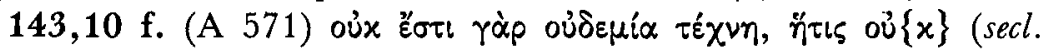

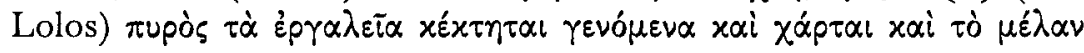

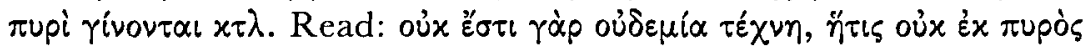

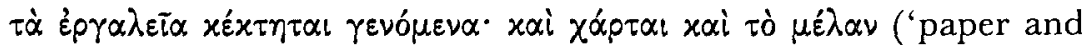
ink') $\pi$ upi rivovial $x \tau \lambda$.

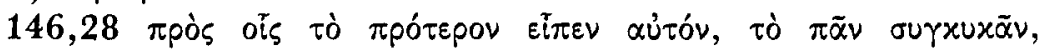

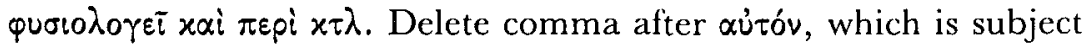

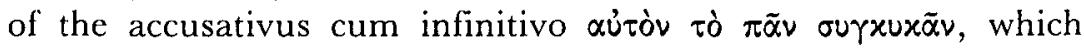
explains $\pi \rho \dot{c} \varsigma$ ois: 'in addition to what he said before, namely that he (viz. ó $\dot{\alpha} \dot{\eta} \rho)$ puts the whole world into turmoil, he also gives an explanation from natural principles etc.'.

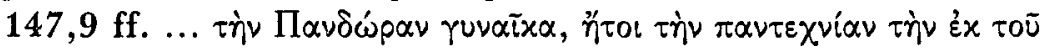

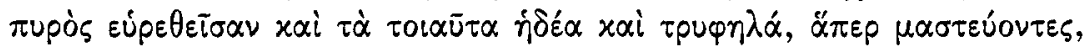

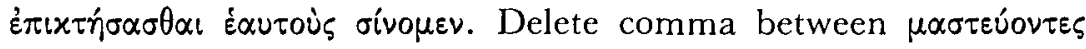

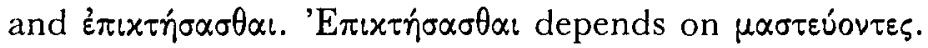

151,16 ff. (A 601): One of the many passages where Tzetzes 


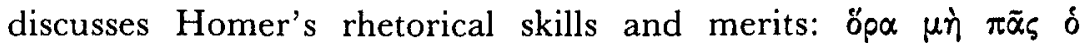

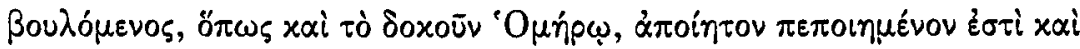

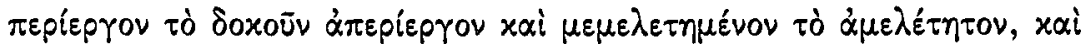

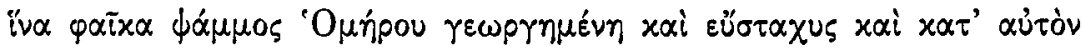

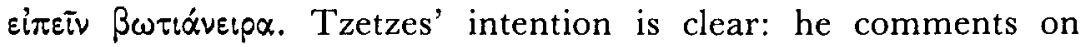
Homer's ars celandi artem: What seems to be simple in fact conceals a remarkable sophistication. Read with changed punctuation: öpa

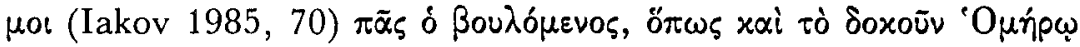

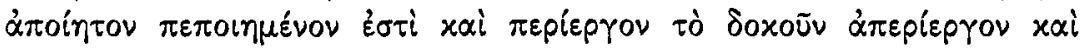

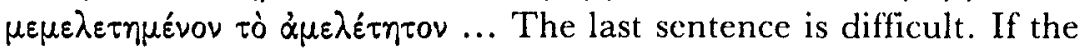
meaning is parallel to what Tzetzes said before, it must be that what seems to be nothing but bare sand turns out to be fertile soil, once Homer puts his hand to the plough. In fact, this is what Tzetzes proceeds to show in 151,20 ff., the sequel to our passage: Homer wants to expatiate on meteorological phenomena, but he avoids a boring, technical cnumeration of facts and instead manages to raise

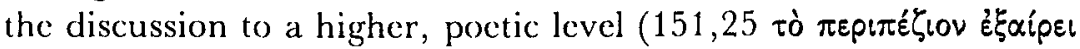

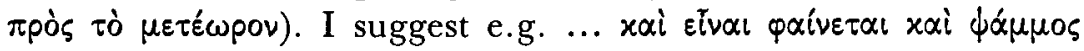

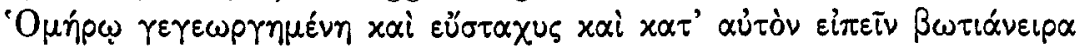
('and even sand worked by Homer seems to be rich in corn and-to use his own words-"man-feeding"').

Minor corrections:

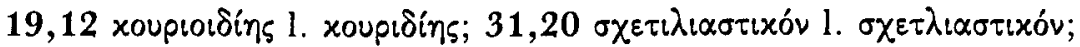

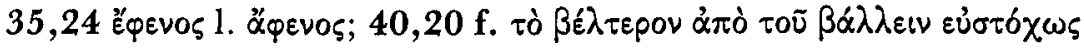

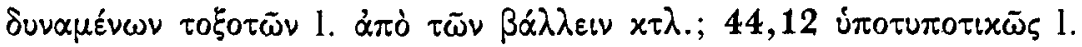

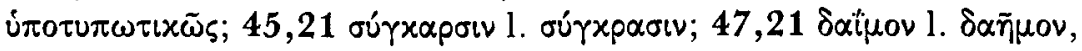

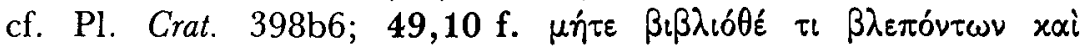

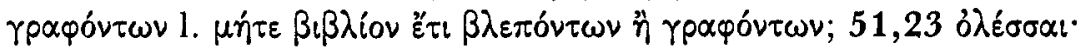

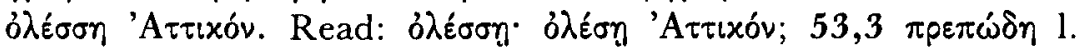

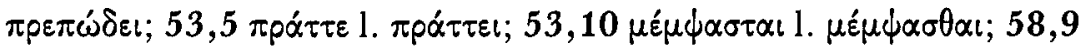

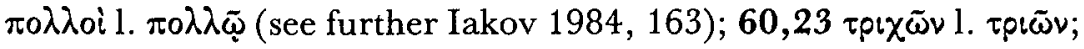

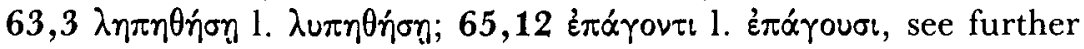

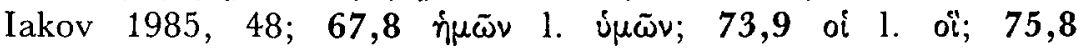

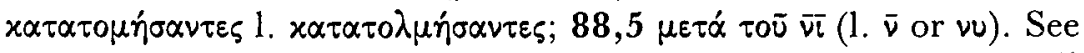

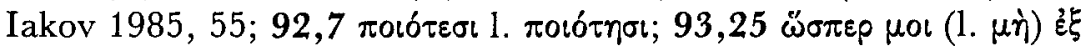

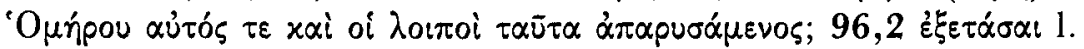

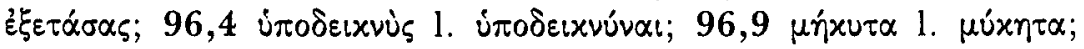




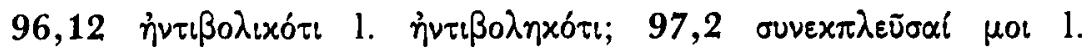

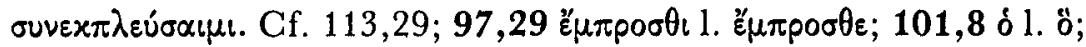

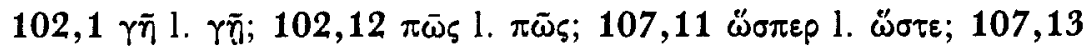

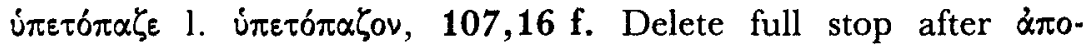

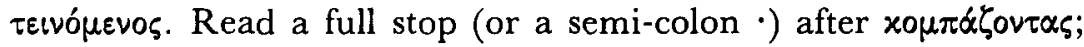

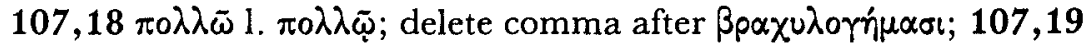

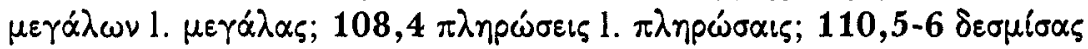

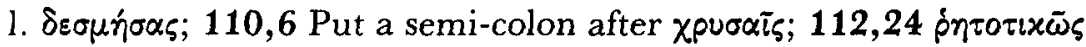

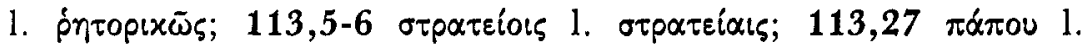

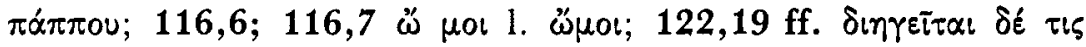

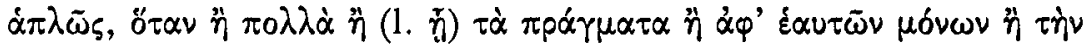

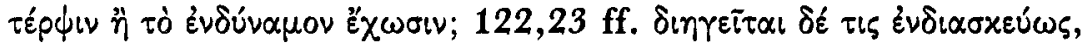

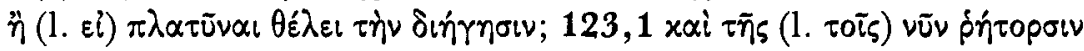

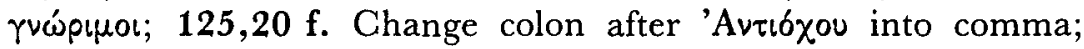

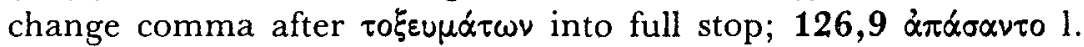

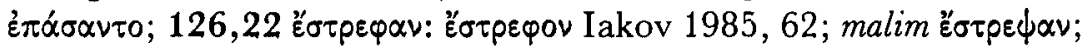

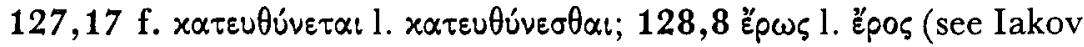

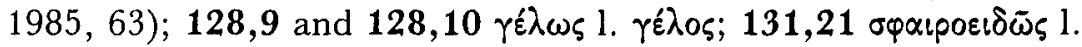

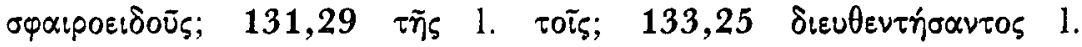

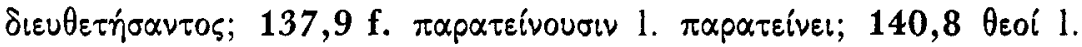

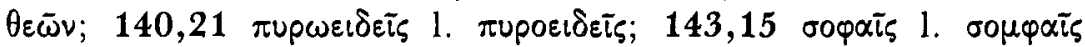

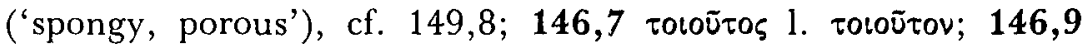

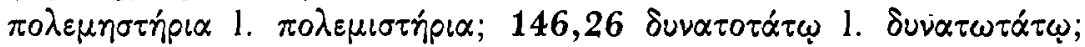

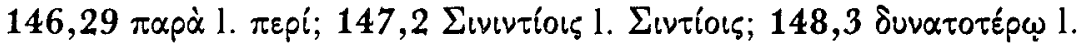

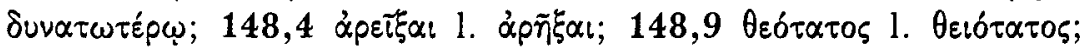

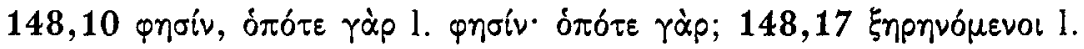
छ̇potvónevol.

1181 HT AmStelveen, Schokland 169 